Published in final edited form as:

Biol Psychiatry. 2020 January 01; 87(1): 34-43. doi:10.1016/j.biopsych.2019.05.025.

\title{
The Opioid-Addicted Tetrapartite Synapse
}

\author{
Anna Kruyer ${ }^{*}, 1$, Vivian C Chioma ${ }^{*}, 1$, Peter W Kalivas ${ }^{1,+}$ \\ ${ }^{1}$ Department of Neuroscience, Medical University of South Carolina, Charleston, SC, USA
}

\begin{abstract}
Opioid administration in preclinical models induces long-lasting adaptations in reward and habit circuitry. The latest research demonstrates that in the nucleus accumbens opioid-induced excitatory synaptic plasticity involves pre- and post-synaptic elements, as well as adjacent astroglial processes and the perisynaptic extracellular matrix. Here we outline opioid-induced modifications within each component of the tetrapartite synapse and provide a neurobiological perspective on how these adaptations converge to produce addiction-related behaviors in rodent models. By incorporating changes observed at each of the excitatory synaptic compartments into a unified framework of opioid-induced glutamate dysregulation, we highlight new avenues for restoring synaptic homeostasis that might limit opioid craving and relapse vulnerability.
\end{abstract}

\section{Keywords}

opioid; presynapse; postsynapse; extracellular matrix; astroglia; plasticity

\section{INTRODUCTION}

Opioid addiction is a chronic disorder, characterized by compulsion to use drugs and a propensity to relapse, even after the acute opioid withdrawal syndrome has elapsed (1). Remarkably, $80 \%$ of heroin users report early use of opioid analgesics (2), supporting the notion that opioid exposure produces long-lasting brain adaptations that can lead to compulsive drug use and seeking. Such brain adaptations manifest in clinical symptoms including impaired cognition (3), deficits in learning, memory, and attention (4), and increased impulsivity $(5,6)$. These impairments are thought to arise from pathological disruptions in prefrontal and subcortical circuits that contribute to an uncontrollable desire to use opioids (craving), and can escalate drug use and increase the likelihood of relapse (6-8). An important consequence of these adaptations is that abstinent heroin users exhibit motivational bias toward heroin-related stimuli $(9,10)$, and elevated cue-reactivity in humans is linked to higher self-reported craving (11). These cognitive changes in opioid

${ }^{+}$Correspondence should be addressed to P.W.K. (173 Ashley Ave, MSC510, Charleston, SC 29425; 843-876-2340, kalivasp@musc.edu).

*Authors contributed equally.

Conflict of interest: None

Publisher's Disclaimer: This is a PDF file of an unedited manuscript that has been accepted for publication. As a service to our customers we are providing this early version of the manuscript. The manuscript will undergo copyediting, typesetting, and review of the resulting proof before it is published in its final citable form. Please note that during the production process errors may be discovered which could affect the content, and all legal disclaimers that apply to the journal pertain. 
users are long-lasting with studies pointing to drug craving and associated persistent deficits in decision-making in former opioid users after nearly two years of abstinence (12). Available medications poorly address the enduring pathophysiology that causes opioid associated environmental stimuli or stress to trigger relapse in humans.

\section{PRECLINICAL MODELS OF OPIOID ADDICTION}

Linking brain cellular pathophysiology with symptoms of human opioid use disorder (OUD) requires preclinical animal models that mimic behavioral phenotypes observed in humans with OUD. For example, rats receiving chronic non-contingent administration of opioids exhibit deficits in learning and memory tasks (13-16) and opioid use and abstinence in rodents involves development of social withdrawal (17), anxiety- and depression-like behaviors $(18,19)$, vulnerability to stressors $(20)$, and decreased motivation for natural rewards (21), similar to symptoms observed in $\operatorname{OUD}(3,4,22-26)$. In self-administration models of OUD, rodents perform operant tasks to receive intravenous opioid infusions, often paired with a conditioning stimulus (cue). Additionally, punishment or aversive/threatening cues can be incorporated into operant training to assess an animal's loss of motivation to acquire the drug reward (27). Animals typically undergo a withdrawal phase after selfadministration with or without extinction training, before undergoing stimulus-induced opioid seeking, at which point a relapse-like state is provoked by exposure to a drugassociated context or cue, an unconditioned stressor, or a priming opioid injection. Selfadministration models can also include measures of use escalation, withdrawal, extinction learning, and relapse, thus incorporating many features of $\operatorname{OUD}(28,29)$. In addition, rodents can be trained to self-administer natural rewards, like sucrose, and neuroadaptations occurring during self-administration, extinction or reinstated seeking of natural rewards can be compared to those observed in animals trained to self-administer opioids (30). In this review, we focus on the pathophysiology induced by non-contingent and self-administered opioids, and cue-induced opioid seeking, where the neurobiological adaptations are not confounded by acute drug pharmacology.

Although dopamine strongly contributes to the reinforcing properties of all drugs of abuse including opioids (reviewed in (31)), a robust literature implicates dysregulated homeostasis at glutamatergic synapses in OUD-associated cognitive impairments and cue reactivity (i.e craving) $(32,33)$. For example, glutamate levels measured by magnetic resonance spectroscopy in reward-associated brain regions in opioid-dependent users correlate positively with measures of impulsivity (34), and opioid-conditioned cues evoke craving in parallel with fMRI measures of increased activity in cortico- and amygdalo-striatal glutamatergic circuits (35). In this review, we explore the preclinical data that identify the cellular underpinnings of these of OUD-induced glutamatergic adaptations found in human imaging studies.

\section{THE TETRAPARTITE GLUTAMATERGIC SYNAPSE}

Glutamatergic neurotransmission subserves cognitive functions, including learning and memory $(36,37)$, and glutamatergic plasticity contributes to addiction- and relapse-related behaviors (38). Although the contribution of glutamatergic plasticity to addiction has been 
more thoroughly characterized in models of psychostimulant use (reviewed in (39)), important roles have been discovered for glutamatergic plasticity in many aspects of opioid addiction, including opioid-related learning $(40,41)$, somatic withdrawal symptoms $(42,43)$, and motivated drug seeking (44). In fact, adaptations shared between the two drug classes, particularly during cued seeking, point to the possibility of a common addiction cellular pathophysiology. However, there we will also point out instances where adaptations are different between psychostimulants and opioids, and bring particular focus to opioidinduced excitatory synaptic adaptations in the nucleus accumbens (NA, Figure 1A), a brain region widely identified as critical for generating motivated behaviors, including opioid use and seeking (45). The glutamatergic cortical and subcortical NA afferents are, in part, topographically organized and make differential contributions to the shell (NAshell) and core (NAcore) subcompartments of the NA (Figure 1A). Research from different laboratories tends to focus on either the NAshell or NAcore, and we will note distinct impacts by opioids on glutamate homeostasis in the two subcompartments. Figure 1A illustrates the general circuitry where glutamatergic synapses undergo enduring and transient plasticity after opioid extinction and during provoked opioid seeking, respectively.

Opioid-induced excitatory synaptic plasticity within the NA involves adaptations at multiple levels, including, but not limited to presynaptic transmitter release (44), the relative abundance and composition of post-synaptic receptors (46), and astroglial regulation of glutamate uptake and release $(47,48)$. More recently, a fourth synaptic compartment was found to be modified by opioid use, the perisynaptic extracellular matrix (ECM) (49). The ECM is a proteinaceous structure that functions as a signaling domain to regulate postsynaptic plasticity (50). Considered together, these four synaptic compartments (the canonical pre- and postsynapse, astroglial perisynaptic processes and the ECM) comprise the tetrapartite synapse (51) (Figure 2) regulate classic forms of pre- and postsynaptic plasticity, such as long-term depression and potentiation (52). More recently, the tetrapartite synapse as an integrated unit has been shown to regulate the maladaptive plasticity produced by repeated use of many addictive drugs, including opioids (53). Below we outline the opioid-associated neuroadaptations in each of the four components, and then integrate these data back into the synaptic tetrapartite structure.

\section{PRE-SYNAPTIC PLASTICITY}

Glutamatergic afferents to the accumbens regulate reinstated opioid seeking $(45,53)$ and inactivation of prelimbic cortical afferents to NAcore disrupts heroin seeking, as well as the increase in extracellular glutamate produced during heroin-primed reinstatement (44). The increase in glutamate release evoked during heroin reinstatement can be blocked by stimulating presynaptic metabotropic glutamate receptor $2 / 3$ (mGluR2/3), which reduces presynaptic glutamate release probability $(54,55)$. Moreover, deletion of mGluR2 in transgenic rats enhances heroin intake during self-administration, potentiates morphineinduced analgesia and augments naloxone-precipitated withdrawal symptoms (56). mGluR2/3 is Gia-coupled and signaling through Gia-coupled receptors is negatively regulated by activator of G-protein signaling 3 (AGS3). Down-regulating AGS3 in NAcore, but not NAshell, potentiates mGluR2/3 signaling and decreases reinstated heroin seeking $(57,58)$. Akin to mGluR2/3, presynaptic cannabinoid1 (CB1) receptors regulate glutamate 
release probability, and intra-accumbens administration of AM251, a CB1 receptor antagonist, diminishes the duration required to extinguish morphine conditioned place preference (CPP), as well as the duration of morphine-induced reinstatement of CPP (59). In addition, the CB1 receptor antagonist, AM4113, dose-dependently suppresses heroin selfadministration (60). Taken together, these data demonstrate that regulating glutamate presynaptic release probability in the NAcore inhibits opioid-seeking.

In addition to presynaptic regulation of glutamate release, neuroadaptations in the excitability of glutamatergic neurons projecting to the accumbens can also regulate opioid use and seeking. For example, the firing frequency in glutamatergic afferents from the amygdala, but not PFC is increased after chronic morphine treatment (61). There are two primary subtypes of projection neurons (medium spiny neurons, MSNs) in NA that express D1- or D2-dopamine receptors(62). In general, plasticity in excitatory signaling within the NA onto D1-MSNs is associated with enhanced opioid seeking $(63,64)$, while signaling at D2-MSNs triggers extinction-related behaviors (65). Within the NAshell there is increased glutamate release probability at synapses on D1-MSN, while at D2-MSN synapses there is decreased release probability after repeated non-contingent morphine (66). Opioid selfadministration also increases glutamatergic release probability on D1-MSNs (67). Alternatively, morphine withdrawal increases c-Fos expression in paraventricular thalamic (PVT) projections to medial NAshell (68). Specifically, PVT to NAshell D2-MSNs show increased postsynaptic currents that are normalized by depotentiating optogenetic photostimulation of PVT terminals synapsing onto D2 MSNs (68). In a $\mu$-opioid receptor (MOR)-null transgenic mouse, targeted rescue of MOR only in striatal D1 MSNs restores morphine-induced CPP (69). Similarly, remifentanil self-administration reduces sensitivity of D1-, but not-D2 MSNs, to MOR modulation in NAshell. While these studies provide insight into cell- and pathway-specific alterations associated with opioid exposure in NAshell (Figure 1B), little is known about such adaptations in the NAcore, or how such changes in release probability are affected by extinction and reinstatement.

\section{POST-SYNAPTIC PLASTICITY}

\section{Spine morphology}

On GABAergic MSNs the principal post-synaptic computational units are dendritic spines (70). Long-term opioid use affects postsynaptic glutamatergic plasticity and disrupting postsynaptic plasticity is sufficient to attenuate reinstated seeking induced by opioid-associated cues or opioid prime $(44,46)$. Opioid administration in preclinical models produces actindependent morphological plasticity in dendritic spines (46), including in spine head diameter, density, and neck length, all of which indicate opioid-induced changes in spine signaling capacity $(71,72)$. Early reports using Golgi staining found that both contingent and non-contingent repeated morphine administration produce wide-spread, enduring reductions in spine density in the NAshell (73). More recent 3-dimensional reconstruction of dye-filled MSNs reveals that heroin self-administration decreases spine head diameter, as well as impairs LTP and LTD in PFC projections to the NAcore $(46,74)$. The thinner spines observed after $14 \mathrm{~d}$ of extinction from heroin exhibited increased surface expression of GluN2B and reduced AMPA/NMDA ratio, measures indicating blunted capacity for 
synaptic plasticity (46). These adaptations are necessary for reinstated drug seeking initiated by heroin prime, and primed drug seeking transiently potentiates glutamatergic inputs to MSNs, as indicated by increased spine density, spine head diameter, and field EPSCs (46).

\section{Receptor composition and density}

In addition to morphological plasticity, opioid administration causes functional plasticity of excitatory synapses due to composition and abundance of post-synaptic receptor insertion. As mentioned above, morphological adaptations in NAcore spines during heroin extinction are associated with increased surface expression of post-synaptic GluN2B and reduced AMPA/NMDA receptor expression (46). Thus, an important mechanism for opioid-induced post-synaptic adaptations involves receptor internalization or downregulation on spines (46), and changes in density or composition of receptors at dendritic spines modulate synaptic output (75). For instance, ionotropic glutamate receptors on neurons in the central amgydala diffuse to dendritic compartments more proximal to the soma after non-contingent morphine administration, facilitating signal propagation (76). Such changes are expected to impact dendritic processing of glutamatergic and GABAergic inputs.

NMDA glutamate receptors (NMDARs) are critically involved in linking glutamate transmission with synaptic plasticity and behavior (77) and in regulating learning and memory processes (78). NMDA receptors are implicated in a number of opioid-mediated addictive behaviors including self-administration $(79,80)$, extinction learning (81), naloxone-precipitated withdrawal severity (82), drug-related contextual learning (83), and the aversion experienced during abstinence (81). Moreover, NMDARs are involved in the LTP and LTD disruption observed after heroin extinction, which is required for reinstated seeking (74). Specifically, heroin self-administration produces enduring upregulation of NMDAR containing GluN2B subunits, and selective blockade of GluN2B in NAcore prevents reinstated heroin seeking (46).

AMPA receptors (AMPARs) are activated at resting membrane potential and are primary mediators of postsynaptic transmission in NA (84). GluA1 and GluA2 AMPAR subunits undergo dynamic activity-dependent trafficking at synapses (85), and induce changes in spine morphology and synaptic strength (86). GluA1 surface expression is increased by experience-dependent plasticity, facilitated by the fact that homomeric GluA1 AMPARs are permeable to $\mathrm{Ca}^{2+}(87,88)$, leading to increased channel conductance, LTP, and synaptic strength $(89,90)$. AMPAR composition and trafficking is highly responsive to opioid administration $(66,91)$. For instance, repeated non-contingent morphine increases surface expression GluA2-lacking AMPARs in hippocampal synapses, limiting the capacity of these synapses to undergo LTD (92). Subsequent studies demonstrated that context-dependent behavioral sensitization to morphine is blocked by disrupting GluA1-phosphorylation in the hippocampus (93), because activity-dependent phosphorylation of GluA1 is linked with its expression at the synaptic surface (94). Heroin-associated cues produce similar downregulation of GluA2 in the infralimbic region of the PFC, which signals to the NAshell (Figure 1A). However, in the absence of increased GluA1 and/or GluA3 expression, as observed in the hippocampus after non-contingent morphine (92), the overall loss of synaptic AMPARs results in synaptic depression that is necessary for cue-induced 
reinstatement of seeking (95). Consistent with these findings are data showing that potentiation of AMPARs in the PFC and NAshell facilitate extinction learning and suppress cued reinstatement (96), while glutamate release and AMPAR stimulation mediate reinstated seeking in NAcore (44).

\section{Cell subtype specificity}

How the postsynaptic adaptations described above segregate according to expression of either D1 or D2 receptors is under active investigation. High levels of NMDARs in the absence of abundant AMPARs (low AMPA/NMDA) are consistent with silent synapses that cannot overcome the NMDAR $\mathrm{Mg}^{2+}$ block needed to generate EPSCs $(97,98)$.

Psychostimulants promote new synapse generation on D1-MSNs in the NAshell that are silenced when the drug is no longer available due to enhanced expression of GluN2Bcontaining NMDARs and reduced AMPA/NMDA (99). During reinstatement, shuttling of $\mathrm{Ca}^{2+}$-permeable AMPARs from extrasynaptic sites to synapses rapidly un-silences synapses on D1-MSNs and produces LTP $(99,100)$. In contrast, synaptic silencing in the NAshell following repeated opioid treatment induces endocytosis of AMPARs on D2 MSNs, weakening spine structure and synaptic strength (Figure 1B) $(46,99)$. As a consequence there is a relative increase in synaptic strength on D1- versus D2-MSNs that promotes opioid seeking $(66,99)$. Whether a similar pattern involving post-synaptic potentiation after psychostimulants and suppressed inhibition after opioids occurs in NAcore is unknown.

\section{ASTROCYTES}

\section{Glutamate transport and release}

Substantial data support a role for astrocytes in regulating synaptic structure and function $(101,102)$. Astroglial modulation of synaptic excitation occurs via glutamate uptake and release that regulates the balance between synaptic and extrasynaptic glutamate (referred to as glutamate homeostasis $(33,103))$. Astrocytes and their perisynaptic astroglial processes (PAPs) express glutamate receptors $(104,105)$, and GLT-1, the principal glutamate transporter that recovers $\sim 90 \%$ of synaptically released glutamate (Figure 2) (106). GLT-1, which is expressed largely on PAPs, and PAP motility regulate access of synaptically released glutamate to the extrasynaptic space and facilitate efficient excitatory synaptic transmission(101).

Akin to other addictive drugs (48), contingent heroin administration reduces astroglial expression of GLT-1 in NAcore $(47,107)$ (Figure 2C). The enduring down-regulation of GLT-1 after heroin extinction impairs clearance of synaptically released glutamate in NAcore, as shown by increased activation of extrasynaptic NMDARs $(47,107)$. Downregulated GLT-1 leads to elevated extracellular glutamate during reinstated seeking for opioids and other addictive drugs measured using in vivo microdialysis or glutamate biosensors $(44,108,109)$. The mechanisms triggering GLT-1 downregulation are unclear, although dysregulated signaling via astroglial glutamate receptors may contribute since stimulation of astroglial mGluR3 increases GLT-1 protein expression (105) (Figure 2C). Thus, it seems likely that the opioid-associated reductions in activity of glutamatergic afferents to the accumbens discussed above contribute to downregulating GLT-1. It should 
be noted that it is not known whether GLT-1 is downregulated during the opioid selfadministration or withdrawal phases of operant training.

Although cue-induced glutamate release in the NAcore is largely TTX sensitive and thus of presynaptic origin (44), astrocytes can also tune presynaptic transmission through astroglial glutamate release directly onto presynaptic mGluR $2 / 3$ autoreceptors (110). Increasing astroglial glutamate release onto mGluR2/3 during cue-induced cocaine reinstatement reduces lever pressing and points to an important role for the cystine-glutamate antiporter in regulating reinstated drug seeking $(110,111)$ (Figure 2). The antiporter imports cystine in a 1:1 exchange for glutamate released extracellularly, which maintains glutamatergic tone on release-regulating presynaptic mGluR2/3 and facilitates glutathione synthesis $(112,113)$. Interestingly, in contrast with psychostimulant use $(114,115)$, surface expression of the catalytic subunit of the antiporter, $\mathrm{xCT}$ is increased in NA after heroin self-administration and extinction (47) (Figure 2). Since activating the antiporter with $\mathrm{N}$-acetylcysteine reduces reinstated heroin and cocaine seeking $(116,117)$, it is interesting to speculate that the heroin-associated increase and cocaine-associated decrease in $\mathrm{xCT}$ on NAcore PAPs may selectively modulate D2- or D1-MSNs(118), respectively, akin to the different drugdependent effects on MSN excitability discussed above.

In addition to cystine-glutamate exchange, other mechanisms of glutamate release by astrocytes have been reported (119), but none have yet been found to contribute to glutamate plasticity observed after extinction from opioids or during reinstated seeking. For instance, while stimulating astroglial MORs increases glutamate transmission in hippocampus via the glutamate channel TREK-1 (120), this channel is also downregulated after chronic opioid use (121).

\section{Morphological plasticity}

Based on the importance of glutamate uptake in cue-induced reinstatement of opioid seeking and the relatively high rates of GLT-1 surface diffusion (122), we began investigating the synaptic proximity of astroglial processes after heroin self-administration. Astroglial retraction from the synapse occurs after extinction from cocaine self-administration (123, 124). Similarly, after heroin extinction the synaptic proximity of the astroglial surface and immunoreactive GLT-1 is reduced (unpublished observations) (Figure 2C). Thus, in addition to reduced uptake of synaptically released glutamate by down-regulated GLT-1, a diminished diffusion barrier resulting from astroglial synaptic retraction may contribute to the spillover of synaptic glutamate during reinstated heroin seeking, akin to what has been observed after extinction from cocaine self-administration (44, 125). Four studies support this possibility. Down-regulated GLT-1 enhances extrasynaptic stimulation of mGluR5 and GluN2b and promotes cocaine seeking $(125,126)$, inhibiting glutamate uptake via intracerebroventricular administration of the GLT-1 antagonist TBOA enhances acquisition of morphine place preference (42), and activating GLT-1 using MS-153 after chronic morphine treatment attenuates the severity of naloxone-precipitated withdrawal (127).

Recently, we found that heroin-associated cues rapidly and transiently increase the proximity of astroglial peripheral processes with the synapse (unpublished observations; Figure 2D) and the transient re-association of the astroglial surface with NAcore synapses 
during heroin reinstatement appears to be compensatory. When the re-association is prevented by knockdown of the actin binding protein ezrin, which is selectively expressed in PAPs (128), cue-induced heroin seeking was potentiated (unpublished observations). Taken together, the enduring reductions in GLT-1 expression and changes in synaptic proximity of astrocyte processes after heroin extinction, along with their morphological plasticity during cue exposure demonstrate a critical role for astrocytes in opioid seeking.

Interestingly, different striatal astrocytes respond selectively to synaptic activity on either D1- or D2-MSNs (129). Thus, the broad distribution of astrocytes with varying degrees of morphological plasticity during reinstated seeking (unpublished observations) may reflect selective changes in synaptic proximity to one or the other MSN subtype. Selective adaptions in GLT-1 expression and astrocyte morphological plasticity in the vicinity of D1 versus D2 synapses would be expected to produce opposite outcomes on opioid seeking, and is an intriguing possibility consistent with the aforementioned selective effects of chronic opioids on D1- versus D2-MSN excitability and morphology.

\section{EXTRACELLULAR MATRIX}

The extracellular matrix (ECM) is a proteinaceous network comprised primarily of glycoproteins and proteoglycans $(130,131)$. It serves as a structural scaffold that tethers neurons and glia via interactions with cellular adhesion molecules (CAMs), such as integrins (53), and constitutes a signaling domain when catalytically activated (130). Global knockdown of neuronal CAMs reduces morphine place preference, supporting ECM involvement in opioid reward (132). ECM degradation by matrix metalloproteinases (MMPs) permits neuronal and astroglial morphological adaptations that contribute to synaptic plasticity (50). MMPs are zinc-dependent endopeptidases that digest ECM proteins to facilitate synaptic remodeling, specifically morphological changes in dendritic spines and trafficking of NMDARs and AMPARs into the synaptic membrane (133, 134). Given MMP involvement in synaptic reconfiguration, their role in pathological addiction-related behaviors has been explored for over a decade (135). MMP-2 and MMP-9 are in the gelatinase family, and have been investigated for their role in drug extinction and reinstatement using in vivo zymography, an assay in which FITC-quenched gelatin acts as a substrate for proteolytic cleavage by activated MMP-2 and $9(49,50)$. Our lab showed that MMP-9 activity transiently increases during cue-induced heroin reinstatement (49), which is required for reinstated cocaine seeking and the transient synaptic potentiation in NAcore associated with reinstated seeking (49). Since cued heroin seeking also potentiates NAcore MSNs, MMP-9 involvement in heroin seeking seems probable. Recently, we discovered that cue-induced heroin seeking is associated with active MMP-2,9 gelatinolytic puncta selectively around D1-MSNs compared to saline controls and heroin extinguished groups (unpublished observations). These observations fit within the canonical perspective that activating D1 MSNs promotes motivated behaviors $(63,64,136)$. Further studies investigating the strength of specific glutamatergic inputs onto D1 MSNs during cued heroin seeking may provide evidence of a relationship between pre- and postsynaptic activity as they relate to MMP induction. 
Chronic morphine treatment activates MMP-9 in spinal cord, which contributes to its antinociceptive effects (137) and attenuates symptoms of morphine withdrawal (138). MMP-9 can be activated by nitrosylation and MMP-9 activation in both spinal cord and NA by opioids or opioid-associated cues results from increased nitric oxide synthesis. Moreover, MMP-9 activation in spinal cord and NA signals into cells via $\beta 1$ - and $\beta 3$-integrin, respectively $(138,139)$, and in NA this signaling is necessary for reinstated cocaine seeking (139). Following heroin extinction, the perineuronal net (PNN) comprised of ECM proteins is reduced in mPFC and NA (140). Interestingly, cued-heroin seeking restores PNN protein expression, and a broad-spectrum MMP inhibitor attenuates cued heroin seeking (140). The apparent paradox of increasing ECM proteins simultaneous with increasing MMP-9 is possible because PNN proteins are not substrates for MMP-9 catalytic activity (141).

\section{NORMALIZING ABERRANT TETRAPARTITE SYNAPTIC HOMEOSTASIS IN OPIOID ADDICTION}

The studies outlined above demonstrate enduring adaptations in each of the four synaptic compartments in NA following repeated non-contingent or self-administered opioids, and opioid seeking is associated with rapid and transient plasticity within each compartment. In some instances the adaptations in one compartment have been experimentally linked to adaptations in other compartments (Figure 2). This is most clear with astroglial retraction and downregulated GLT-1, which are necessary for presynaptic glutamate spillover, induction of MMP activity, and morphological and physiological postsynaptic potentiation. Although much work remains to fully characterize how the tetrapartite synaptic compartments interact to regulate plasticity, it is clear that each of the four compartments are altered by opioid use and that these alterations regulate the initiation and intensity of opioidseeking in rodent models of OUD.

Our developing understanding of tetrapartite synaptic physiology and pathophysiology has led to novel drug development strategies targeted to adaptations in each tetrapartite compartment. In the presynaptic compartment, the most tractable possibility is using mGluR2/3 agonists to reduce opioid seeking, although concerns have been raised due to parallel decreases in seeking of natural rewards. Promising postsynaptic receptor pharmacological manipulations include blocking mGluR5, which prevents conditioned morphine reward (142). Additionally, intracerebroventricular NMDAR and AMPAR antagonism during context extinction impairs morphine-induced reinstatement of CPP and increases NA c-fos expression (143-145). Also, heroin cue-induced and primed reinstatement and accompanying increases in spine density in NAcore are impaired by ifenprodil, a GluN2B antagonist (46).

Several studies focus on reversing glutamate spillover following chronic opioid use by restoring function and/or expression of GLT-1 or the cystine-glutamate antiporter with $\mathrm{N}$ acetylcysteine (NAC) or ceftriaxone, and thereby reducing heroin cue and prime reinstatement $(107,117,146)$. Other compounds such as propentofylline (methylxanthine adenosine uptake inhibitor) and clavulanic acid ( $\beta$-lactam antibiotic) enhance expression of GLT-1 and inhibit morphine place preference $(147,148)$. It remains unknown whether these 
astroglial-targeting restorative agents are effective at preventing changes in astroglial synaptic proximity that contribute to cued opioid seeking. Finally, therapeutics based on opioid-induced adaptations in the ECM seem furthest from development given the difficulties encountered in clinical trials using MMP-9 inhibitors in treating neuroinflammation (149).

\section{CONCLUSIONS}

This review makes clear that understanding the molecular mechanisms underpinning how the four tetrapartite compartments interact to regulate one another is necessary for understanding normal synaptic plasticity, as well as the aberrant physiology induced by opioids. The preclinical data justify this research direction as a potential source of novel pharmacotherapies for OUD. However, there is need for a larger research effort into fundamental mechanisms of tetrapartite synaptic integration before we will likely be able to develop comprehensive biological rationales for reversing opioid-induced tetrapartite pathophysiology as a means to control OUD.

\section{ACKNOWLEDGEMENTS AND DISCLOSURES}

This work was supported by DA007288, DA044782 (A.K.), DA046143 (V.C.), and DA003906, DA012513 (P.W.K.) from the National Institutes of Health. The authors report no biomedical financial interests or potential conflicts of interest.

\section{REFERENCES}

1. Koob GF, Volkow ND (2016): Neurobiology of addiction: a neurocircuitry analysis. Lancet Psychiatry. 3:760-773. [PubMed: 27475769]

2. Jones CM (2013): Heroin use and heroin use risk behaviors among nonmedical users of prescription opioid pain relievers - United States, 2002-2004 and 2008-2010. Drug Alcohol Depend. 132:95100. [PubMed: 23410617]

3. Wollman SC, Hauson AO, Hall MG, Connors EJ, Allen KE, Stern MJ, et al. (2019): Neuropsychological functioning in opioid use disorder: A research synthesis and meta-analysis. Am J Drug Alcohol Abuse. 45:11-25. [PubMed: 30359116]

4. Arias F, Arnsten JH, Cunningham CO, Coulehan K, Batchelder A, Brisbane M, et al. (2016): Neurocognitive, psychiatric, and substance use characteristics in opioid dependent adults. Addict Behav. 60:137-143. [PubMed: 27131800]

5. Lee TM, Zhou WH, Luo XJ, Yuen KS, Ruan XZ, Weng XC (2005): Neural activity associated with cognitive regulation in heroin users: A fMRI study. Neurosci Lett. 382:211-216. [PubMed: 15925092]

6. Jones JD, Vadhan NP, Luba RR, Comer SD (2016): The effects of heroin administration and drug cues on impulsivity. J Clin Exp Neuropsychol. 38:709-720. [PubMed: 27062912]

7. Goldstein RZ, Volkow ND (2011): Dysfunction of the prefrontal cortex in addiction: neuroimaging findings and clinical implications. Nat Rev Neurosci. 12:652-669. [PubMed: 22011681]

8. Schippers MC, Binnekade R, Schoffelmeer AN, Pattij T, De Vries TJ (2012): Unidirectional relationship between heroin self-administration and impulsive decision-making in rats. Psychopharmacology (Berl). 219:443-452. [PubMed: 21887498]

9. Marissen MA, Franken IH, Waters AJ, Blanken P, van den Brink W, Hendriks VM (2006): Attentional bias predicts heroin relapse following treatment. Addiction. 101:1306-1312. [PubMed: 16911730]

10. Zhao Q, Li H, Hu B, Li Y, Gillebert CR, Mantini D, et al. (2017): Neural Correlates of DrugRelated Attentional Bias in Heroin Dependence. Front Hum Neurosci. 11:646. [PubMed: 29410620] 
11. Carter BL, Tiffany ST (1999): Meta-analysis of cue-reactivity in addiction research. Addiction. 94:327-340. [PubMed: 10605857]

12. Biernacki K, McLennan SN, Terrett G, Labuschagne I, Rendell PG (2016): Decision-making ability in current and past users of opiates: A meta-analysis. Neurosci Biobehav Rev. 71:342-351. [PubMed: 27649645]

13. Dougherty KD, Walsh TJ, Bailey S, Schlussman S, Grasing K (1996): Acquisition of a morris water maze task is impaired during early but not late withdrawal from morphine. Pharmacol Biochem Behav. 55:227-235. [PubMed: 8951959]

14. Sala M, Braida D, Leone MP, Calcaterra P, Frattola D, Gori E (1994): Chronic morphine affects working memory during treatment and withdrawal in rats: possible residual long-term impairment. Behav Pharmacol. 5:570-580. [PubMed: 11224236]

15. Spain JW, Newsom GC (1991): Chronic opioids impair acquisition of both radial maze and Ymaze choice escape. Psychopharmacology (Berl). 105:101-106. [PubMed: 1745703]

16. Tramullas M, Martinez-Cue C, Hurle MA (2007): Chronic methadone treatment and repeated withdrawal impair cognition and increase the expression of apoptosis-related proteins in mouse brain. Psychopharmacology (Berl). 193:107-120. [PubMed: 17384938]

17. Lutz PE, Ayranci G, Chu-Sin-Chung P, Matifas A, Koebel P, Filliol D, et al. (2014): Distinct mu, delta, and kappa opioid receptor mechanisms underlie low sociability and depressive-like behaviors during heroin abstinence. Neuropsychopharmacology. 39:2694-2705. [PubMed: 24874714]

18. Haydari S, Miladi-Gorji H, Mokhtari A, Safari M (2014): Effects of voluntary exercise on anxietylike behavior and voluntary morphine consumption in rat pups borne from morphinedependent mothers during pregnancy. Neurosci Lett. 578:50-54. [PubMed: 24973610]

19. Alizadeh M, Zahedi-Khorasani M, Miladi-Gorji H (2018): Treadmill exercise attenuates the severity of physical dependence, anxiety, depressive-like behavior and voluntary morphine consumption in morphine withdrawn rats receiving methadone maintenance treatment. Neurosci Lett. 681:73-77. [PubMed: 29859324]

20. Bai Y, Belin D, Zheng X, Liu Z, Zhang Y (2017): Acute stress worsens the deficits in appetitive behaviors for social and sexual stimuli displayed by rats after long-term withdrawal from morphine. Psychopharmacology (Berl). 234:1693-1702. [PubMed: 28280885]

21. Zhang D, Zhou X, Wang X, Xiang X, Chen H, Hao W (2007): Morphine withdrawal decreases responding reinforced by sucrose self-administration in progressive ratio. Addict Biol. 12:152157. [PubMed: 17508986]

22. Darke S, Swift W, Hall W (1994): Prevalence, severity and correlates of psychological morbidity among methadone maintenance clients. Addiction. 89:211-217. [PubMed: 8173487]

23. Scherrer JF, Svrakic DM, Freedland KE, Chrusciel T, Balasubramanian S, Bucholz KK, et al. (2014): Prescription opioid analgesics increase the risk of depression. J Gen Intern Med. 29:491499. [PubMed: 24165926]

24. Langdon KJ, Dove K, Ramsey S (2019): Comorbidity of opioid-related and anxiety-related symptoms and disorders. Curr Opin Psychol. 30:17-23. [PubMed: 30711906]

25. Back SE, Gros DF, Price M, LaRowe S, Flanagan J, Brady KT, et al. (2015): Laboratoryinduced stress and craving among individuals with prescription opioid dependence. Drug Alcohol Depend. 155:60-67. [PubMed: 26342626]

26. Lubman DI, Garfield JB, Gwini SM, Cheetham A, Cotton SM, Yucel M, et al. (2018): Dynamic associations between opioid use and anhedonia: A longitudinal study in opioid dependence. $\mathrm{J}$ Psychopharmacol. 32:957-964. [PubMed: 30130143]

27. Verharen JPH, van den Heuvel M, Luijendijk M, Vanderschuren L, Adan RAH (2019): Corticolimbic mechanisms of behavioral inhibition under threat of punishment. J Neurosci.

28. Shaham Y, Shalev U, Lu L, De Wit H, Stewart J (2003): The reinstatement model of drug relapse: history, methodology and major findings. Psychopharmacology (Berl). 168:3-20. [PubMed: 12402102]

29. Crombag HS, Bossert JM, Koya E, Shaham Y (2008): Review. Context-induced relapse to drug seeking: a review. Philos Trans R Soc Lond B Biol Sci. 363:3233-3243. [PubMed: 18640922] 
30. Bobadilla AC, Garcia-Keller C, Heinsbroek JA, Scofield MD, Chareunsouk V, Monforton C, et al. (2017): Accumbens Mechanisms for Cued Sucrose Seeking. Neuropsychopharmacology. 42:23772386. [PubMed: 28726801]

31. Solinas M, Belujon P, Fernagut PO, Jaber M, Thiriet N (2018): Dopamine and addiction: what have we learned from 40 years of research. J Neural Transm (Vienna).

32. Ross S, Peselow E (2009): The neurobiology of addictive disorders. Clin Neuropharmacol. 32:269-276. [PubMed: 19834992]

33. Kalivas PW, Lalumiere RT, Knackstedt L, Shen H (2009): Glutamate transmission in addiction. Neuropharmacology. 56 Suppl 1:169-173. [PubMed: 18675832]

34. Liu XL, Li L, Li JN, Tang JH, Rong JH, Liu B, et al. (2017): Quantifying absolute glutamate concentrations in nucleus accumbens of prescription opioid addicts by using (1)H MRS. Brain Behav. 7:e00769. [PubMed: 28828225]

35. Li Q, Wang Y, Zhang Y, Li W, Yang W, Zhu J, et al. (2012): Craving correlates with mesolimbic responses to heroin-related cues in short-term abstinence from heroin: an event-related fMRI study. Brain Res. 1469:63-72. [PubMed: 22759909]

36. Robbins TW, Murphy ER (2006): Behavioural pharmacology: 40+ years of progress, with a focus on glutamate receptors and cognition. Trends Pharmacol Sci. 27:141-148. [PubMed: 16490260]

37. Platt SR (2007): The role of glutamate in central nervous system health and disease--a review. Vet J. 173:278-286. [PubMed: 16376594]

38. Kalivas PW (2008): Addiction as a pathology in prefrontal cortical regulation of corticostriatal habit circuitry. Neurotox Res. 14:185-189. [PubMed: 19073425]

39. Bobadilla AC, Heinsbroek JA, Gipson CD, Griffin WC, Fowler CD, Kenny PJ, et al. (2017): Corticostriatal plasticity, neuronal ensembles, and regulation of drug-seeking behavior. Prog Brain Res. 235:93-112. [PubMed: 29054293]

40. Liu P, Che X, Yu L, Yang X, An N, Song W, et al. (2017): Uridine attenuates morphine-induced conditioned place preference and regulates glutamate/GABA levels in $\mathrm{mPFC}$ of mice. Pharmacol Biochem Behav. 163:74-82. [PubMed: 29024680]

41. Vatankhah M, Sarihi A, Komaki A, Shahidi S, Haghparast A (2018): AMN082-a metabotropic glutamate receptor type 7 allosteric agonist in the NAc facilitates extinction and inhibits the reinstatement of morphine-induced conditioned place preference in male rats. Brain Res Bull. 140:28-33. [PubMed: 29605484]

42. Sekiya Y, Nakagawa T, Ozawa T, Minami M, Satoh M (2004): Facilitation of morphine withdrawal symptoms and morphine-induced conditioned place preference by a glutamate transporter inhibitor DL-threo-beta-benzyloxyaspartate in rats. Eur J Pharmacol. 485:201-210. [PubMed: 14757142]

43. Nakagawa T, Satoh M (2004): Involvement of glial glutamate transporters in morphine dependence. Ann N Y Acad Sci. 1025:383-388. [PubMed: 15542740]

44. LaLumiere RT, Kalivas PW (2008): Glutamate release in the nucleus accumbens core is necessary for heroin seeking. J Neurosci. 28:3170-3177. [PubMed: 18354020]

45. Scofield MD, Heinsbroek JA, Gipson CD, Kupchik YM, Spencer S, Smith AC, et al. (2016): The Nucleus Accumbens: Mechanisms of Addiction across Drug Classes Reflect the Importance of Glutamate Homeostasis. Pharmacol Rev. 68:816-871. [PubMed: 27363441]

46. Shen H, Moussawi K, Zhou W, Toda S, Kalivas PW (2011): Heroin relapse requires long-term potentiation-like plasticity mediated by NMDA2b-containing receptors. Proc Natl Acad Sci U S A. 108:19407-19412. [PubMed: 22084102]

47. Shen HW, Scofield MD, Boger H, Hensley M, Kalivas PW (2014): Synaptic glutamate spillover due to impaired glutamate uptake mediates heroin relapse. J Neurosci. 34:5649-5657. [PubMed: 24741055]

48. Roberts-Wolfe DJ, Kalivas PW (2015): Glutamate Transporter GLT-1 as a Therapeutic Target for Substance Use Disorders. CNS Neurol Disord Drug Targets. 14:745-756. [PubMed: 26022265]

49. Smith AC, Kupchik YM, Scofield MD, Gipson CD, Wiggins A, Thomas CA, et al. (2014): Synaptic plasticity mediating cocaine relapse requires matrix metalloproteinases. Nat Neurosci. 17:1655-1657. [PubMed: 25326689]

50. Huntley GW (2012): Synaptic circuit remodelling by matrix metalloproteinases in health and disease. Nat Rev Neurosci. 13:743-757. [PubMed: 23047773] 
51. Dityatev A, Seidenbecher CI, Schachner M (2010): Compartmentalization from the outside: the extracellular matrix and functional microdomains in the brain. Trends Neurosci. 33:503-512. [PubMed: 20832873]

52. Dityatev A, Rusakov DA (2011): Molecular signals of plasticity at the tetrapartite synapse. Curr Opin Neurobiol. 21:353-359. [PubMed: 21277196]

53. Mulholland PJ, Chandler LJ, Kalivas PW (2016): Signals from the Fourth Dimension Regulate Drug Relapse. Trends Neurosci. 39:472-485. [PubMed: 27173064]

54. Bossert JM, Busch RF, Gray SM (2005): The novel mGluR2/3 agonist LY379268 attenuates cueinduced reinstatement of heroin seeking. Neuroreport. 16:1013-1016. [PubMed: 15931079]

55. Bossert JM, Poles GC, Sheffler-Collins SI, Ghitza UE (2006): The mGluR2/3 agonist LY379268 attenuates context- and discrete cue-induced reinstatement of sucrose seeking but not sucrose selfadministration in rats. Behav Brain Res. 173:148-152. [PubMed: 16834996]

56. Gao JT, Jordan CJ, Bi GH, He Y, Yang HJ, Gardner EL, et al. (2018): Deletion of the type 2 metabotropic glutamate receptor increases heroin abuse vulnerability in transgenic rats. Neuropsychopharmacology. 43:2615-2626. [PubMed: 30283001]

57. Bowers MS, McFarland K, Lake RW, Peterson YK, Lapish CC, Gregory ML, et al. (2004): Activator of $\mathrm{G}$ protein signaling 3: a gatekeeper of cocaine sensitization and drug seeking. Neuron. 42:269-281. [PubMed: 15091342]

58. Yao L, McFarland K, Fan P, Jiang Z, Inoue Y, Diamond I (2005): Activator of G protein signaling 3 regulates opiate activation of protein kinase A signaling and relapse of heroin-seeking behavior. Proc Natl Acad Sci U S A. 102:8746-8751. [PubMed: 15937104]

59. Khaleghzadeh-Ahangar H, Haghparast A (2015): Intra-accumbal CB1 receptor blockade reduced extinction and reinstatement of morphine. Physiol Behav. 149:212-219. [PubMed: 26057574]

60. He XH, Jordan CJ, Vemuri K, Bi GH, Zhan J, Gardner EL, et al. (2019): Cannabinoid CB1 receptor neutral antagonist AM4113 inhibits heroin self-administration without depressive side effects in rats. Acta Pharmacol Sin. 40:365-373. [PubMed: 29967454]

61. Yuan K, Sheng H, Song J, Yang L, Cui D, Ma Q, et al. (2017): Morphine treatment enhances glutamatergic input onto neurons of the nucleus accumbens via both disinhibitory and stimulating effect. Addict Biol. 22:1756-1767. [PubMed: 27549902]

62. Gerfen CR, Surmeier DJ (2011): Modulation of striatal projection systems by dopamine. Annual Review of Neuroscience. 34:441-466.

63. Lobo MK, Nestler EJ (2011): The striatal balancing act in drug addiction: distinct roles of direct and indirect pathway medium spiny neurons. Front Neuroanat. 5:41. [PubMed: 21811439]

64. Heinsbroek JA, Neuhofer DN, Griffin WC 3rd, Siegel GS, Bobadilla AC, Kupchik YM, et al. (2017): Loss of Plasticity in the D2-Accumbens Pallidal Pathway Promotes Cocaine Seeking. J Neurosci. 37:757-767. [PubMed: 28123013]

65. Hearing M (2019): Prefrontal-accumbens opioid plasticity: Implications for relapse and dependence. Pharmacol Res. 139:158-165. [PubMed: 30465850]

66. Hearing MC, Jedynak J, Ebner SR, Ingebretson A, Asp AJ, Fischer RA, et al. (2016): Reversal of morphine-induced cell-type-specific synaptic plasticity in the nucleus accumbens shell blocks reinstatement. Proc Natl Acad Sci U S A. 113:757-762. [PubMed: 26739562]

67. James AS, Chen JY, Cepeda C, Mittal N, Jentsch JD, Levine MS, et al. (2013): Opioid selfadministration results in cell-type specific adaptations of striatal medium spiny neurons. Behav Brain Res. 256:279-283. [PubMed: 23968589]

68. Zhu Y, Wienecke CF, Nachtrab G, Chen X (2016): A thalamic input to the nucleus accumbens mediates opiate dependence. Nature. 530:219-222. [PubMed: 26840481]

69. Cui Y, Ostlund SB, James AS, Park CS, Ge W, Roberts KW, et al. (2014): Targeted expression of mu-opioid receptors in a subset of striatal direct-pathway neurons restores opiate reward. Nat Neurosci. 17:254-261. [PubMed: 24413699]

70. Hausser M, Spruston N, Stuart GJ (2000): Diversity and dynamics of dendritic signaling. Science. 290:739-744. [PubMed: 11052929]

71. Chidambaram SB, Rathipriya AG, Bolla SR, Bhat A, Ray B, Mahalakshmi AM, et al. (2019): Dendritic spines: Revisiting the physiological role. Prog Neuropsychopharmacol Biol Psychiatry. 92:161-193. [PubMed: 30654089] 
72. Williams SR, Stuart GJ (2003): Role of dendritic synapse location in the control of action potential output. Trends Neurosci. 26:147-154. [PubMed: 12591217]

73. Robinson TE, Gorny G, Savage VR, Kolb B (2002): Widespread but regionally specific effects of experimenter- versus self-administered morphine on dendritic spines in the nucleus accumbens, hippocampus, and neocortex of adult rats. Synapse. 46:271-279. [PubMed: 12373743]

74. Shen H, Kalivas PW (2013): Reduced LTP and LTD in prefrontal cortex synapses in the nucleus accumbens after heroin self-administration. Int J Neuropsychopharmacol. 16:1165-1167. [PubMed: 23110855]

75. Sjostrom PJ, Rancz EA, Roth A, Hausser M (2008): Dendritic excitability and synaptic plasticity. Physiol Rev. 88:769-840. [PubMed: 18391179]

76. Beckerman MA, Ogorodnik E, Glass MJ (2013): Acute morphine associated alterations in the subcellular location of the AMPA-GluR1 receptor subunit in dendrites of neurons in the mouse central nucleus of the amygdala: comparisons and contrasts with other glutamate receptor subunits. Synapse. 67:692-704. [PubMed: 23564315]

77. Glass MJ (2010): The role of functional postsynaptic NMDA receptors in the central nucleus of the amygdala in opioid dependence. Vitam Horm. 82:145-166. [PubMed: 20472137]

78. Hansen KB, Yi F, Perszyk RE, Furukawa H, Wollmuth LP, Gibb AJ, et al. (2018): Structure, function, and allosteric modulation of NMDA receptors. J Gen Physiol. 150:1081-1105. [PubMed: 30037851]

79. Glick SD, Maisonneuve IM, Dickinson HA, Kitchen BA (2001): Comparative effects of dextromethorphan and dextrorphan on morphine, methamphetamine, and nicotine selfadministration in rats. Eur J Pharmacol. 422:87-90. [PubMed: 11430918]

80. Semenova S, Danysz W, Bespalov A (1999): Low-affinity NMDA receptor channel blockers inhibit acquisition of intravenous morphine self-administration in naive mice. Eur J Pharmacol. 378:1-8. [PubMed: 10478558]

81. Myers KM, Carlezon WA, Jr. (2010): Extinction of drug- and withdrawal-paired cues in animal models: relevance to the treatment of addiction. Neurosci Biobehav Rev. 35:285-302. [PubMed: 20109490]

82. Trujillo KA, Akil H (1991): Inhibition of morphine tolerance and dependence by the NMDA receptor antagonist MK-801. Science. 251:85-87. [PubMed: 1824728]

83. Tzschentke TM, Schmidt WJ (1995): N-methyl-D-aspartic acid-receptor antagonists block morphine-induced conditioned place preference in rats. Neurosci Lett. 193:37-40. [PubMed: 7566661]

84. Diering GH, Huganir RL (2018): The AMPA Receptor Code of Synaptic Plasticity. Neuron. 100:314-329. [PubMed: 30359599]

85. Wang JQ, Arora A, Yang L, Parelkar NK, Zhang G, Liu X, et al. (2005): Phosphorylation of AMPA receptors: mechanisms and synaptic plasticity. Mol Neurobiol. 32:237-249. [PubMed: 16385140]

86. Russo SJ, Dietz DM, Dumitriu D, Morrison JH, Malenka RC, Nestler EJ (2010): The addicted synapse: mechanisms of synaptic and structural plasticity in nucleus accumbens. Trends Neurosci. 33:267-276. [PubMed: 20207024]

87. Liu SJ, Zukin RS (2007): Ca2+-permeable AMPA receptors in synaptic plasticity and neuronal death. Trends Neurosci. 30:126-134. [PubMed: 17275103]

88. Clem RL, Barth A (2006): Pathway-specific trafficking of native AMPARs by in vivo experience. Neuron. 49:663-670. [PubMed: 16504942]

89. Isaac JT, Ashby MC, McBain CJ (2007): The role of the GluR2 subunit in AMPA receptor function and synaptic plasticity. Neuron. 54:859-871. [PubMed: 17582328]

90. Kauer JA, Malenka RC (2007): Synaptic plasticity and addiction. Nat Rev Neurosci. 8:844-858. [PubMed: 17948030]

91. Glass MJ, Lane DA, Colago EE, Chan J, Schlussman SD, Zhou Y, et al. (2008): Chronic administration of morphine is associated with a decrease in surface AMPA GluR1 receptor subunit in dopamine D1 receptor expressing neurons in the shell and non-D1 receptor expressing neurons in the core of the rat nucleus accumbens. Exp Neurol. 210:750-761. [PubMed: 18294632] 
92. Billa SK, Liu J, Bjorklund NL, Sinha N, Fu Y, Shinnick-Gallagher P, et al. (2010): Increased insertion of glutamate receptor 2-lacking alpha-amino-3-hydroxy-5-methyl-4-isoxazole propionic acid (AMPA) receptors at hippocampal synapses upon repeated morphine administration. Mol Pharmacol. 77:874-883. [PubMed: 20159947]

93. Xia Y, Portugal GS, Fakira AK, Melyan Z, Neve R, Lee HT, et al. (2011): Hippocampal GluA1containing AMPA receptors mediate context-dependent sensitization to morphine. $\mathrm{J}$ Neurosci. 31:16279-16291. [PubMed: 22072679]

94. Ehlers MD (2000): Reinsertion or degradation of AMPA receptors determined by activitydependent endocytic sorting. Neuron. 28:511-525. [PubMed: 11144360]

95. Van den Oever MC, Goriounova NA, Li KW, Van der Schors RC, Binnekade R, Schoffelmeer AN, et al. (2008): Prefrontal cortex AMPA receptor plasticity is crucial for cue-induced relapse to heroin-seeking. Nat Neurosci. 11:1053-1058. [PubMed: 19160503]

96. Chen W, Wang Y, Sun A, Zhou L, Xu W, Zhu H, et al. (2016): Activation of AMPA receptor in the infralimbic cortex facilitates extinction and attenuates the heroin-seeking behavior in rats. Neurosci Lett. 612:126-131. [PubMed: 26639425]

97. Dong Y, Taylor JR, Wolf ME, Shaham Y (2017): Circuit and Synaptic Plasticity Mechanisms of Drug Relapse. J Neurosci. 37:10867-10876. [PubMed: 29118216]

98. Kerchner GA, Nicoll RA (2008): Silent synapses and the emergence of a postsynaptic mechanism for LTP. Nat Rev Neurosci. 9:813-825. [PubMed: 18854855]

99. Graziane NM, Sun S, Wright WJ, Jang D, Liu Z, Huang YH, et al. (2016): Opposing mechanisms mediate morphine- and cocaine-induced generation of silent synapses. Nat Neurosci. 19:915-925. [PubMed: 27239940]

100. Gipson CD, Kupchik YM, Shen H, Reissner KJ, Thomas CA, Kalivas PW (2013): Relapse induced by cues predicting cocaine depends on rapid, transient synaptic potentiation. Neuron. 77:867-872. [PubMed: 23473317]

101. Allen NJ (2014): Astrocyte regulation of synaptic behavior. Annu Rev Cell Dev Biol. 30:439463. [PubMed: 25288116]

102. Bernardinelli Y, Muller D, Nikonenko I (2014): Astrocyte-synapse structural plasticity. Neural Plast. 2014:232105. [PubMed: 24511394]

103. Coulter DA, Eid T (2012): Astrocytic regulation of glutamate homeostasis in epilepsy. GLIA. 60:1215-1226. [PubMed: 22592998]

104. Skowronska K, Obara-Michlewska M, Zielinska M, Albrecht J (2019): NMDA Receptors in Astrocytes: In Search for Roles in Neurotransmission and Astrocytic Homeostasis. Int J Mol Sci. 20.

105. Aronica E, Gorter JA, Ijlst-Keizers H, Rozemuller AJ, Yankaya B, Leenstra S, et al. (2003): Expression and functional role of mGluR3 and mGluR5 in human astrocytes and glioma cells: opposite regulation of glutamate transporter proteins. Eur J Neurosci. 17:2106-2118. [PubMed: 12786977]

106. Danbolt NC (2001): Glutamate uptake. Prog Neurobiol. 65:1-105. [PubMed: 11369436]

107. Shen HW, Gipson CD, Huits M, Kalivas PW (2014): Prelimbic cortex and ventral tegmental area modulate synaptic plasticity differentially in nucleus accumbens during cocaine-reinstated drug seeking. Neuropsychopharmacology. 39:1169-1177. [PubMed: 24232172]

108. McFarland K, Lapish CC, Kalivas PW (2003): Prefrontal glutamate release into the core of the nucleus accumbens mediates cocaine-induced reinstatement of drug-seeking behavior. $\mathrm{J}$ Neurosci. 23:3531-3537. [PubMed: 12716962]

109. Madayag A, Lobner D, Kau KS, Mantsch JR, Abdulhameed O, Hearing M, et al. (2007): Repeated N-acetylcysteine administration alters plasticity-dependent effects of cocaine. $\mathrm{J}$ Neurosci. 27:13968-13976. [PubMed: 18094234]

110. Scofield MD, Boger HA, Smith RJ, Li H, Haydon PG, Kalivas PW (2015): Gq-DREADD Selectively Initiates Glial Glutamate Release and Inhibits Cue-induced Cocaine Seeking. Biol Psychiatry. 78:441-451. [PubMed: 25861696]

111. Baker DA, Shen H, Kalivas PW (2002): Cystine/glutamate exchange serves as the source for extracellular glutamate: modifications by repeated cocaine administration. Amino Acids. 23:161162. [PubMed: 12373531] 
112. Lewerenz J, Hewett SJ, Huang Y, Lambros M, Gout PW, Kalivas PW, et al. (2013): The cystine/ glutamate antiporter system $\mathrm{x}(\mathrm{c})(-)$ in health and disease: from molecular mechanisms to novel therapeutic opportunities. Antioxid Redox Signal. 18:522-555. [PubMed: 22667998]

113. Forman HJ, Zhang H, Rinna A (2009): Glutathione: overview of its protective roles, measurement, and biosynthesis. Mol Aspects Med. 30:1-12. [PubMed: 18796312]

114. Reissner KJ, Gipson CD, Tran PK, Knackstedt LA, Scofield MD, Kalivas PW (2015): Glutamate transporter GLT-1 mediates N-acetylcysteine inhibition of cocaine reinstatement. Addict Biol. 20:316-323. [PubMed: 24612076]

115. Knackstedt LA, LaRowe S, Mardikian P, Malcolm R, Upadhyaya H, Hedden S, et al. (2009): The role of cystine-glutamate exchange in nicotine dependence in rats and humans. Biol Psychiatry. 65:841-845. [PubMed: 19103434]

116. Baker DA, McFarland K, Lake RW, Shen H, Tang XC, Toda S, et al. (2003): Neuroadaptations in cystine-glutamate exchange underlie cocaine relapse. Nat Neurosci. 6:743-749. [PubMed: 12778052]

117. Zhou W, Kalivas PW (2008): N-acetylcysteine reduces extinction responding and induces enduring reductions in cue- and heroin-induced drug-seeking. Biol Psychiatry. 63:338-340. [PubMed: 17719565]

118. Martin R, Bajo-Graneras R, Moratalla R, Perea G, Araque A (2015): GLIAL CELL SIGNALING. Circuit-specific signaling in astrocyte-neuron networks in basal ganglia pathways. Science. 349:730-734. [PubMed: 26273054]

119. Woo DH, Han KS, Shim JW, Yoon BE, Kim E, Bae JY, et al. (2012): TREK-1 and Best1 channels mediate fast and slow glutamate release in astrocytes upon GPCR activation. Cell. 151:25-40. [PubMed: 23021213]

120. Woo DH, Bae JY, Nam MH, An H, Ju YH, Won J, et al. (2018): Activation of Astrocytic muopioid Receptor Elicits Fast Glutamate Release Through TREK-1-Containing K2P Channel in Hippocampal Astrocytes. Front Cell Neurosci. 12:319. [PubMed: 30319359]

121. Wang H, Wang S, Zhang K, Wang H, Lan L, Ma X, et al. (2017): Aquaporin 4 Forms a Macromolecular Complex with Glutamate Transporter 1 and Mu Opioid Receptor in Astrocytes and Participates in Morphine Dependence. J Mol Neurosci. 62:17-27. [PubMed: 28341892]

122. Murphy-Royal C, Dupuis JP, Varela JA, Panatier A, Pinson B, Baufreton J, et al. (2015): Surface diffusion of astrocytic glutamate transporters shapes synaptic transmission. Nat Neurosci. 18:219-226. [PubMed: 25581361]

123. Scofield MD, Li H, Siemsen BM, Healey KL, Tran PK, Woronoff N, et al. (2016): Cocaine SelfAdministration and Extinction Leads to Reduced Glial Fibrillary Acidic Protein Expression and Morphometric Features of Astrocytes in the Nucleus Accumbens Core. Biol Psychiatry. 80:207215. [PubMed: 26946381]

124. Testen A, Sepulveda-Orengo MT, Gaines CH, Reissner KJ (2018): Region-Specific Reductions in Morphometric Properties and Synaptic Colocalization of Astrocytes Following Cocaine SelfAdministration and Extinction. Frontiers in cellular neuroscience. 12:246. [PubMed: 30147645]

125. Smith ACW, Scofield MD, Heinsbroek JA, Gipson CD, Neuhofer D, Roberts-Wolfe DJ, et al. (2017): Accumbens nNOS Interneurons Regulate Cocaine Relapse. J Neurosci. 37:742-756. [PubMed: 28123012]

126. Gipson CD, Reissner KJ, Kupchik YM, Smith AC, Stankeviciute N, Hensley-Simon ME, et al. (2013): Reinstatement of nicotine seeking is mediated by glutamatergic plasticity. Proc Natl Acad Sci U S A. 110:9124-9129. [PubMed: 23671067]

127. Nakagawa T, Ozawa T, Shige K, Yamamoto R, Minami M, Satoh M (2001): Inhibition of morphine tolerance and dependence by MS-153, a glutamate transporter activator. Eur J Pharmacol. 419:39-45. [PubMed: 11348628]

128. Lavialle M, Aumann G, Anlauf E, Prols F, Arpin M, Derouiche A (2011): Structural plasticity of perisynaptic astrocyte processes involves ezrin and metabotropic glutamate receptors. Proc Natl Acad Sci U S A. 108:12915-12919. [PubMed: 21753079]

129. Martin R, Bajo-Graneras R, Moratalla R, Perea G, Araque A (2015): Circuit-specific signaling in astrocyte-neuron networks in basal ganglia pathways. Science. 349:730-734. [PubMed: 26273054] 
130. Wright JW, Harding JW (2009): Contributions of matrix metalloproteinases to neural plasticity, habituation, associative learning and drug addiction. Neural Plast. 2009:579382. [PubMed: 20169175]

131. Bosman FT, Stamenkovic I (2003): Functional structure and composition of the extracellular matrix. J Pathol. 200:423-428. [PubMed: 12845610]

132. Ishiguro H, Liu QR, Gong JP, Hall FS, Ujike H, Morales M, et al. (2006): NrCAM in addiction vulnerability: positional cloning, drug-regulation, haplotype-specific expression, and altered drug reward in knockout mice. Neuropsychopharmacology. 31:572-584. [PubMed: 16123759]

133. Michaluk P, Mikasova L, Groc L, Frischknecht R, Choquet D, Kaczmarek L (2009): Matrix metalloproteinase-9 controls NMDA receptor surface diffusion through integrin beta1 signaling. $\mathrm{J}$ Neurosci. 29:6007-6012. [PubMed: 19420267]

134. Michaluk P, Wawrzyniak M, Alot P, Szczot M, Wyrembek P, Mercik K, et al. (2011): Influence of matrix metalloproteinase MMP-9 on dendritic spine morphology. J Cell Sci. 124:3369-3380. [PubMed: 21896646]

135. Wright JW, Masino AJ, Reichert JR, Turner GD, Meighan SE, Meighan PC, et al. (2003): Ethanol-induced impairment of spatial memory and brain matrix metalloproteinases. Brain Res. 963:252-261. [PubMed: 12560131]

136. Kravitz AV, Tye LD, Kreitzer AC (2012): Distinct roles for direct and indirect pathway striatal neurons in reinforcement. Nat Neurosci. 15:816-818. [PubMed: 22544310]

137. Nakamoto K, Kawasaki S, Kobori T, Fujita-Hamabe W, Mizoguchi H, Yamada K, et al. (2012): Involvement of matrix metalloproteinase- 9 in the development of morphine tolerance. Eur J Pharmacol. 683:86-92. [PubMed: 22445883]

138. Liu WT, Han Y, Liu YP, Song AA, Barnes B, Song XJ (2010): Spinal matrix metalloproteinase-9 contributes to physical dependence on morphine in mice. J Neurosci. 30:7613-7623. [PubMed: 20519536]

139. Garcia-Keller C, Neuhofer D, Bobadilla AC, Spencer S, Chioma V, Monforton C, et al. (2019): Extracellular matrix signaling through B3 integrin mediates cocaine cue-induced transient synaptic plasticity and relapse. Biological Psychiatry. in press.

140. Van den Oever MC, Lubbers BR, Goriounova NA, Li KW, Van der Schors RC, Loos M, et al. (2010): Extracellular matrix plasticity and GABAergic inhibition of prefrontal cortex pyramidal cells facilitates relapse to heroin seeking. Neuropsychopharmacology. 35:2120-2133. [PubMed: 20592718]

141. Theocharis AD, Skandalis SS, Gialeli C, Karamanos NK (2016): Extracellular matrix structure. Adv Drug Deliv Rev. 97:4-27. [PubMed: 26562801]

142. Popik P, Wrobel M (2002): Morphine conditioned reward is inhibited by MPEP, the mGluR5 antagonist. Neuropharmacology. 43:1210-1217. [PubMed: 12527470]

143. Siahposht-Khachaki A, Fatahi Z, Yans A, Khodagholi F, Haghparast A (2017): Involvement of AMPA/Kainate Glutamate Receptor in the Extinction and Reinstatement of Morphine-Induced Conditioned Place Preference: A Behavioral and Molecular Study. Cell Mol Neurobiol. 37:315328. [PubMed: 27053349]

144. Siahposht-Khachaki A, Fatahi Z, Haghparast A (2016): Reduction of the Morphine Maintenance by Blockade of the NMDA Receptors during Extinction Period in Conditioned Place Preference Paradigm of Rats. Basic Clin Neurosci. 7:341-350. [PubMed: 27872695]

145. Siahposht-Khachaki A, Ezzatpanah S, Razavi Y, Haghparast A (2018): NMDA receptor dependent changes in c-fos and p-CREB signaling following extinction and reinstatement of morphine place preference. Neurosci Lett. 662:147-151. [PubMed: 29054430]

146. Hodebourg R, Murray JE, Fouyssac M, Puaud M, Everitt BJ, Belin D (2018): Heroin seeking becomes dependent on dorsal striatal dopaminergic mechanisms and can be decreased by Nacetylcysteine. Eur J Neurosci.

147. Schroeder JA, Tolman NG, McKenna FF, Watkins KL, Passeri SM, Hsu AH, et al. (2014): Clavulanic acid reduces rewarding, hyperthermic and locomotor-sensitizing effects of morphine in rats: a new indication for an old drug? Drug Alcohol Depend. 142:41-45. [PubMed: 24998018] 
148. Sweitzer SM, Schubert P, DeLeo JA (2001): Propentofylline, a glial modulating agent, exhibits antiallodynic properties in a rat model of neuropathic pain. J Pharmacol Exp Ther. 297:1210 1217. [PubMed: 11356948]

149. Vafadari B, Salamian A, Kaczmarek L (2016): MMP-9 in translation: from molecule to brain physiology, pathology, and therapy. J Neurochem. 139 Suppl 2:91-114. 


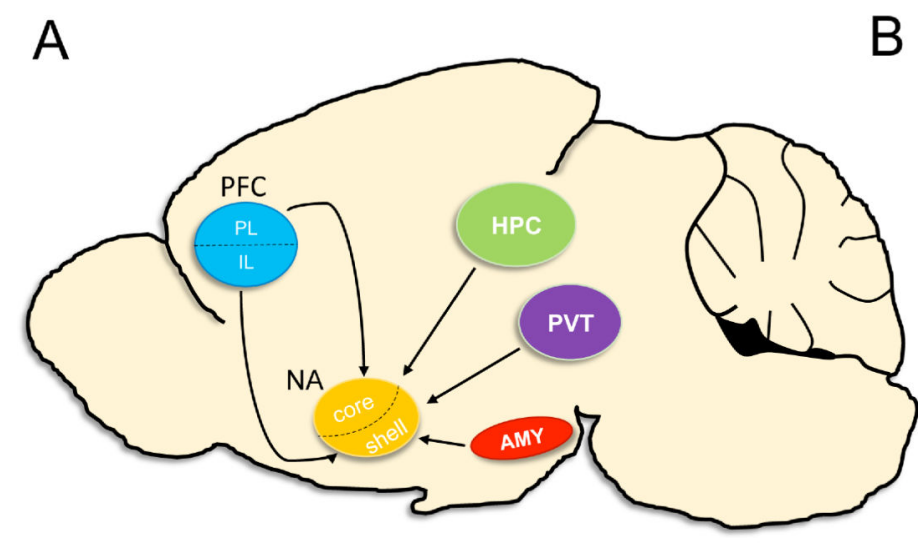

Motivated Seeking
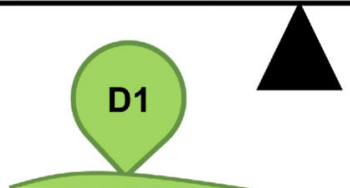

Increased glutamate release probability following opioid intake $(63,64)$

Reduced sensitivity to MOR modulation after opioid selfadmin (64)

Selective restoration of MORs rescues morphine preference (68)

Increase in synaptic strength after opioid treatment promoting opioid seeking (94)

Figure 1.

(A) Glutamatergic afferents from cortical and subcortical brain regions converge onto nucleus accumbens (NA, with core and shell subcompartments indicated). Following repeated exposure to opioids, these projections undergo maladaptive plasticity contributing to aberrant drug seeking after periods of extinction (Figure 2). (B) Schematic outlining classic D1 vs D2 dichotomy with D1 medium spiny neurons (MSN) firing predominating during opioid seeking, while D2 MSNs are activated by extinction and the aversion associated with opioid withdrawal. Bullets indicate cell-type specific observations discussed in the text. Prefrontal cortex (PFC) subdivided into prelimbic (PL) and infralimbic (IL) with dashed line; hippocampus (HPC), paraventricular thalamus (PVT), and amygdala (AMY). 

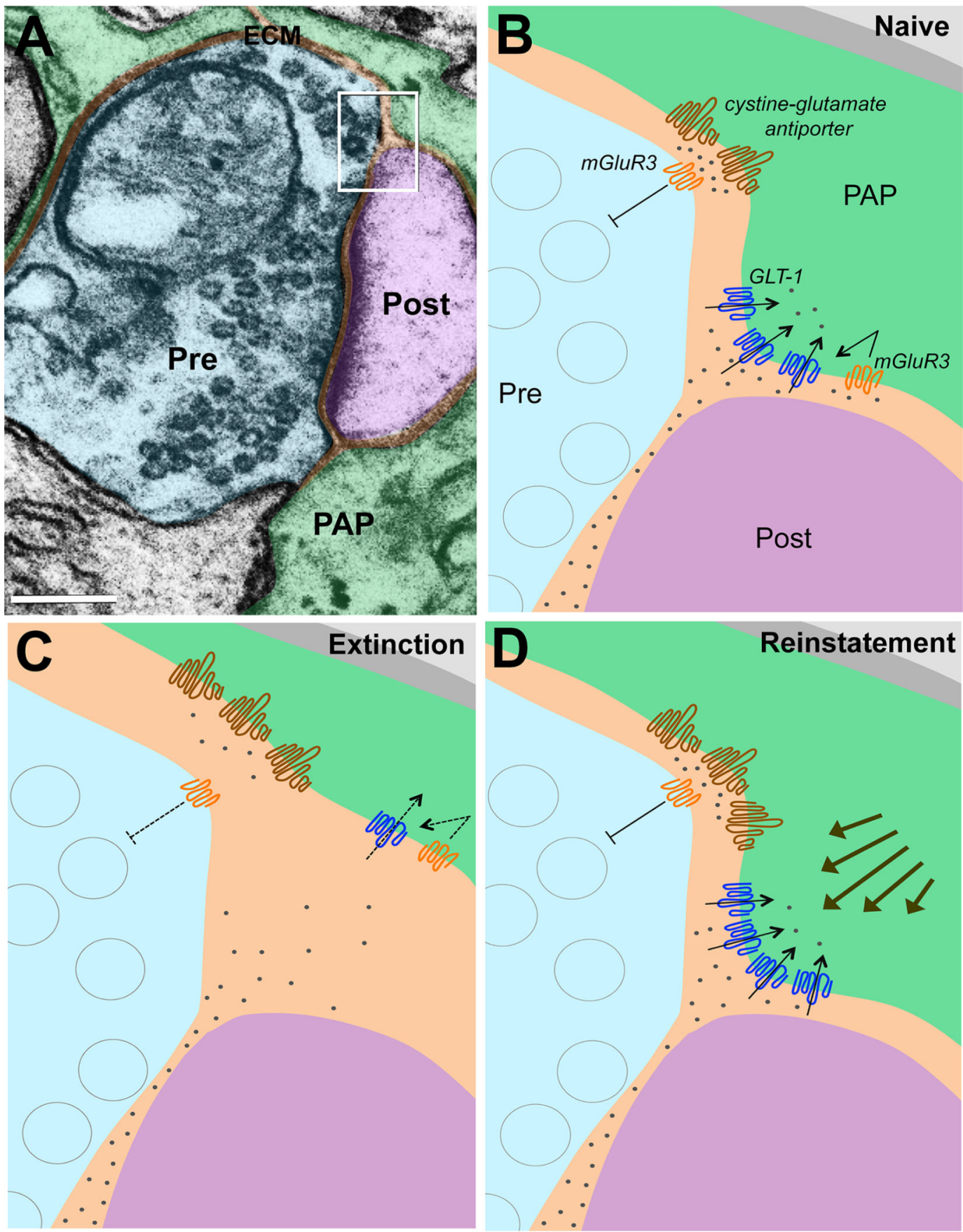

Figure 2.

Tetrapartite synaptic structure and regulation of synaptic glutamate homeostasis by astroglial processes. Tetrapartite synaptic structure demonstrated in an electron micrograph from the mouse hippocampus (A, scale bar= 200nm). Presynaptic afferent (blue) with synaptic vesicles and mitochondrion. Post-synaptic terminal (purple), with electron-dense postsynaptic density. Nearby astroglial perisynaptic processes (PAP, green) surround the synaptic cleft. The perisynaptic extracellular matrix (orange) serves as a signaling medium between all cellular components of the synapse. (B) Under normal physiological conditions, GLT-1 
(blue) on PAPs is responsible for the majority of glutamate (small gray circles) uptake. Stimulation of astroglial mGluR3 (orange) has been linked to upregulating GLT-1 (105). Astroglial glutamate release through the cystine-glutamate antiporter (brown) can modulate release at glutamatergic terminals by stimulating presynaptic mGluR2/3 (orange) that negatively regulate presynaptic glutamate release probability. (C) After extinction from heroin or cocaine self-administration, NAcore astrocytes retract from the synapse, reducing their capacity for glutamate uptake through GLT-1 (blue). Downregulated expression of GLT-1 may result in part from reduced stimulation of astroglial mGluR3 (orange). Astroglial retraction may also disrupt presynaptic tone on $\mathrm{mGluR} 2 / 3$ via cystine-glutamate exchange. (D) During 15 minutes of cued heroin seeking, astroglial processes exhibit increased synaptic proximity as well as increased surface expression of GLT-1, both of which serve to attenuate seeking behavior by hindering synaptic glutamate spillover into the extracellular space. Micrograph in (A) was generated by A.K at the Electron Microscopy Resource Center at The Rockefeller University. 